Investigating the validity of the Wong and Law Emotional Intelligence Scale in a Nepali student sample

Sochos, A. ${ }^{1}$, Regmi, M. ${ }^{2}$, \& Basent, D.M. ${ }^{3}$

\footnotetext{
${ }^{1}$ University of Bedfordsire, UK

2 Tribhuwan University, Nepal

${ }^{3}$ Pacific University, India
}

To be published in the Asian Journal of Social Psychology 


\begin{abstract}
This paper investigates the cross-cultural validity of the WLEIS. Two samples of university students were recruited: 504 from a Nepali University and 260 from a UK university. In relation to culture, SEM analyses provided support for the scale's configural invariance and the configural, metric, and scalar invariance of two if its subscales. Evidence for measurement invariance was also found in relation to gender in both samples. Tentative analyses suggested that the correlation between self and other emotion appraisal was stronger among UK participants and that UK participants scored higher on the Other Emotion Appraisal subscale. No gender differences on emotional intelligence were found in the Napali sample, while among UK students, males scored higher on Regulation of Emotion and lower on Other Emotion Appraisal than females. In the Nepali sample, science students scored lower on various aspects of emotional intelligence than humanities students.
\end{abstract}

Keywords: emotional intelligence, culture, Nepal, measurement invariance, education. 


\section{Investigating the validity of the Wong and Law Emotional Intelligence Scale in a Nepali student sample}

Emotional intelligence is defined as the general capacity to think about emotion (Izard et al., 2001), but also as the specific abilities to use emotional information (Lyubomirsky et al., 2005), reason about emotions (MacCann et al., 2004), perceive and identify emotions (Nowicki \& Duke, 1994), and manage emotional intensity (Gross, 1998). The term also relates to flexibility, achievement motivation, self-regard, and happiness (Mayer, Roberts, Barsade, 2008). EI is linked with positive outcomes in childhood (Schultz, Izard, \& Bear, 2004) and adulthood, including relationship well-being (Bracket et al., 2006), good negotiation and decision making skills (Day \& Carroll, 2004), psychological well-being (Brackett \& Mayer, 2003), and positive health behaviours ((Trinidad \& Johnson, 2002).

Various measures have been developed to assess EI and as the concept is increasingly receiving international attention, investigating the cross-cultural validity of both concept and methods of measurement is important. Different cultures often ascribe different meanings to emotional expressions and follow different social norms about how emotions are experienced and communicated. Such cultural diversity also has implications on how EI should be empirically assessed in different contexts. For example, while western cultures tend to encourage the open and demonstrable expression of emotion, Asians tend to value emotional restrain and containment (Trompenaars \& Hampden-Turner, 1998). Research suggests that as a result, Far Eastern participants tend to use the midpoints of scales with emotional content more often, compared to westerners (Chen, Lee, and Stevenson, 1995).

The Wong and Law Emotional Intelligence Scale -WLEIS (Wong \& Law, 2002) is one of the most widely used, assessing four dimensions: self emotion appraisal (SEA), others' emotion appraisal (OEA), use of emotion (UoE), and regulation of emotion (RoE). 
Studies report significant concordance between WLEIS and peer reports (Joseph \& Newman, 2010) and provide evidence for the scale's discriminant, criterion, and factor validity (Wong \& Law, 2002) as well as measurement invariance (Kong, 2017; Libbrecht et al., 2014). Utilising an item-response theory approach, LaPalme and colleagues (2016) found that the OEA subscale was the main source of invariance between a US and a Chinese sample, while Libbrecht and colleagues (2014) presented only partial support for the scale's scalar invariance.

One limitation of the cross-cultural validation of the WLEIS is that, to the best of our knowledge, research so far has been conducted in either western countries or far-eastern territories under significant historical western influence (e.g. Singapore, Hong-Kong). Such influence may have predisposed local individuals towards internalising western ways of psychological functioning, including how they experience and manage emotions. Research suggests that central processes captured by WLEIS, such as the triggering, understanding, and regulation of emotions, are significantly influenced by cultural norms, beliefs, and values Matsumoto \& Hwang, 2011). As these authors indicate, the individualism vs. collectivism framework has significantly informed work in the area.

To the best of our knowledge, no study so far has investigated the validity of the measure in south-eastern Asia. Nepal is a country in that region that has received relatively little western influence, retaining to a significant degree its traditional, agricultural, and collectivist character. Although the British influence on the country's foreign policy has been obvious in the past centuries, Nepal was never occupied by the British, or any other western power. Moreover, Nepal presents an additional interest as it is one of the poorest nations in the world, plagued in recent years by a violent civil war and a series of natural disasters. As enhancing emotional intelligence can be critical in resilience building (Schneider, Lyons, \& Khazon, 2013), employing appropriate research tools to inform community support is 
important. Testing the cross-cultural validity of WLEIS in Nepal would strengthen the scale's evidence-base and make the instrument easier to utilise in that part of the world.

Nepali higher education is significant for upgrading the country's resources of resilience in a world in which knowledge exchange and capacity building often involves international cooperation. After graduation, current university students in Nepal are expected to occupy influential positions in both the public and private sectors, exercise leadership, and contribute to the development of the country's coping resources. Moreover, research suggests that emotion is central to learning and that emotional intelligence is linked to a number of student attributes that facilitate the learning process, such as self-directedness, academic resilience, engagement, and capacity to achieve good academic outcomes ((D'Mello \& Graesser, 2012; Zhoc et al., 2020). For these reasons, we aimed to investigate the validity of WLEIS in a Nepali student sample. Based on the scale's previous cross-cultural validation studies referred to above, we hypothesised that the WLEIS factor structure will be confirmed in both a Nepali and a UK sample and it will be invariant across cultures, gender, age, and field of study.

\section{Method}

\section{Design}

This was a cross-sectional validation study.

\section{Measures}

A brief demographic questionnaire and the WLEIS (Wong \& Law, 2002) were used. WLEIS consists of 16 items rated on a five-point Likert scale (Strongly Disagree/1 to Strongly Agree/5). Items 1-4 comprise the SEA subscale, items 5-8 comprise OEA, items 912 comprise UoE, and items 13-16 comprise RoE (Appendix 1). 


\section{Participants}

Participants included 504 students from (removed for anonymity) University in Nepal and 260 from (removed) University in the UK. Among the Nepali students, 229 were male and 275 female; 144 were undergraduate (mean age $=20.3, \mathrm{SD}=1.3$ ) and 360 postgraduate (mean age $=23.5, \mathrm{SD}=.5$ ); 182 studied in the humanities faculty, 153 in science, and 169 in management. All Nepali students had a good command of the English language. Among the UK students, 101 were males and 159 females; 202 undergraduates (mean age $=22.72, \mathrm{SD}=$ 5.53 ) and 58 postgraduates (mean age $=26.78, \mathrm{SD}=6.54$ ); no information on study subject was available. Data on ethnicity were available only for the UK sample: $56 \%$ were white, $20 \%$ of black African and Caribbean background, $6 \%$ of Asian backgrounds, $10 \%$ were white non-British, and $8 \%$ of mixed ethnicities. Sample size was determined according to the requirements set in the SEM literature (Wolf et al., 2013).

\section{Procedure}

Participants were recruited by research assistants on campus during class breaks. They received written and verbal information about the study and provided written consent; they completed the questionnaire in a private space and returned it to the assistant. Research assistants were not involved in the teaching of students. The study received ethical clearance from the appropriate ethics committees in both universities involved.

\section{Results}

No more that $1 \%$ of data per variable were missing from either sample. Missing value analysis indicated that missing data involved just up to three participants across five items and suggested no pattern. According to the literature, any missing values below 5\% should not be regarded as a source of bias. Missing data were replaced using linear interpolation in 
SPSS, as this method satisfies several properties such as consistency and scale invariance (Pownuk \& Kreinovich, 2017). When the core analyses were repeated without replacing the missing values, the findings did not change (Appendix 2). Converting the data to z-scores, we identified 5 univariate outliers across 5 items (see Supplementary Tables for item descriptives and intercorrelations before the removal of outliers). No evidence of univariate skewness or kurtosis was found as all values fell within the required -1 to 1 range. However, Mardia's coefficient was 33.20 suggesting departure from multivariate normality. Obtaining the Mahalanobis distance coefficient, the p values of 29 observations significantly departed from the centroid. When we removed all univariate and multivariate outliers multivariate kurtosis was not significantly affected. As the slight skew was on the left, we converted all scores to $\log 10$ of (larger score +1 - score) and removed the most extreme multivariate outliers. The value of multivariate kurtosis fell below 6, suggesting that now deviation from multivariate normality was not considerable (Bentler, 2006).

Interclass correlation coefficients suggested no nesting effects, either between the two universities $(\mathrm{ICC}=.01)$ or the three Nepali faculties $(\mathrm{ICC}=.02)$. The scale's four-factor structure was tested in the Nepali sample using structural equation modelling in AMOS and the resulting model had a good fit $\left(\chi^{2}(96)=152.56, \mathrm{p}<.001 ;\right.$ AGFI=.94; CFI=.93;

$\mathrm{SRMR}=.04, \mathrm{RMSEA}=.03 ; \mathrm{AIC}=232.56$. We evaluated model fit against six widely utilised indexes of different types (Kline, 2010). Chi square, an absolute index, is the most commonly used; however, it can b affected by sample size failing to reject poor models in small samples and rejecting good models in large ones. We also utilised two more absolute indices AGFI ( $\geq$ .90 for a good fit) and SRMR (<.08 for a good fit), the non-centrality index RMSEA ( $\leq .05$ for a good fit) and the comparative index CFI ( $\geq .90$ for an acceptable fit, $\geq .95$ for a good fit). These compare the proposed and baseline models and are relatively unaffected by sample 
size. We also included an information theoretic index, AIC, that finds a balance between model fit and model complexity (the lower the value, the better the fit).

To test the internal consistency of the four subscales, we tested the tau-equivalent model (Graham, 2006), also utilising the NFI index (( $\geq .95$ for a good fit). All models attained a very good fit. Indices for SEA were $\chi^{2}(2)=1.81, \mathrm{p}=.455 ; \mathrm{CFI}=1, \mathrm{NFI}=.97$, RMSEA $=.00, \operatorname{SRMR}=.02$, and $\mathrm{AIC}=25.81$; for OEA $\chi^{2}(2)=3.24, \mathrm{p}=.198 ; \mathrm{CFI}=99$, $\mathrm{NFI}=.98, \mathrm{RMSEA}=.04, \mathrm{SRMR}=.02, \mathrm{AIC}=27.24 ;$ for $\operatorname{UoE} \chi^{2}(2)=11.66, \mathrm{p}=.003 ; \mathrm{CFI}=.96$, $\mathrm{NFI}=.95, \mathrm{RMSEA}=.09, \mathrm{SRMR}=.04, \mathrm{AIC}=35.66$; for $\operatorname{RoE} \chi^{2}(2)=3.99, \mathrm{p}=.136 ; \mathrm{CFI}=99$, $\mathrm{NFI}=.98, \mathrm{RMSEA}=.05, \mathrm{SRMR}=.02, \mathrm{AIC}=27.99$. Cronbach alpha values for all subscales were below .7 ( $\alpha=.45$ for SEQ, $\alpha=.61$ for OEA, $\alpha=.6$ for UoE, $\alpha=.67$ for RoE). This was not surprising considering the tendency of this coefficient to underestimate scale reliability, particularly on a small number of items (Graham, 2006).

As a next step, we tested the invariance of the measure and its four subscales across country, gender, and subject of study by conducting a multi-group confirmatory factor analysis (CFA) in AMOS. This is a widely accepted method of testing measurement invariance between different participant groups (Byrne, 2004; van de Schoot, Lugtig, \& Hox , 2012). We first defined the two country groups (Nepal and UK) and run the CFA models without setting any constraints on factor loadings or item intercepts. As shown in Table 1, all models had a good fit, evidencing the scales' configural invariance in relation to culture. In the next step we tested the scales' metric invariance, by constraining all factor loadings to be equal between the two groups, while allowing intercepts to vary freely. Based on the relevant literature, we considered as evidence of metric invariance changes of $\leq .02$ in CFI, $\leq .03$ in RMSEA, <.03 in SRMR and <.02 in McDonald's NonCentrality Index, which we also added as a good coefficient of model change (Chen, 2007; Rutkowski \& Svetina, 2014). The decision to accept or reject the metric invariance 
hypothesis was made on what the majority of the indices indicated. Non-substantial changes in the fit indices of the new model indicated that item-to-factor weights were equivalent between the two samples and therefore the metric invariance hypothesis was supported. When that was the case, we proceeded to the next step, testing the scalar invariance of the measure by also constraining the intercepts. Change in fit indices in the third model was evaluated again as above, except that the acceptable change cut-off for $\triangle$ RMSEA and $\triangle$ CFI in this step was $\leq .01$ (Li et al., 2015; Rutkowski \& Svetina, 2014). Non-significant change in the fit indices of the new model suggested that, across groups, mean differences in a latent variable corresponded to all mean differences in the shared variance of the individual items loading to that variable and, therefore, the scalar invariance hypothesis was supported. According to the findings (Table 1), the metric invariance hypothesis in relation to culture was not supported for WLEIS or the SEA subscale, while the scalar invariance hypothesis was not supported for OEA.

The same procedure involving the whole scale was repeated in relation to gender in the two samples separately and in relation to study subject in the Nepali sample (Table 2). Evidence of configural, metric, and scalar invariance was found in the Nepali sample in relation to both variables tested, while evidence of configural and metric invariance was found in relation to gender in the UK sample.

Utilising composite scores based on the latent variables, we compared correlations between the subscales across the UK and Nepal samples. None of the correlations were significantly different except between SEA and OEA (Table 3). MANOVA suggested that UK participants had higher scores on the OEA than the Nepali $\left(\mathrm{F}_{4,718}=12.34, \mathrm{p}<.001\right.$, Wilks =.94). No gender differences were found in the Nepali sample $\left(\mathrm{F}_{4,488}=2.37\right.$, $\mathrm{p}=.052$, Wilks $=.98$ ), while among UK participants males scored higher in RoE and lower in OEA compared to females $\left(\mathrm{F}_{4,207}=6.80, \mathrm{p}<.001\right.$, Wilks $\left.=.88\right)$. In the Nepali sample 
humanities students scored higher than science students in SEA, UoE, and RoE, and higher than management students in OEA; management students scored higher than science students in UoE.

\section{Discussion}

The present findings strengthen the evidence for the cross-cultural validity of WLEIS, although specific areas for consideration have been identified. Difficulties in establishing metric invariance in the overall scale and the SEA suggest that although the four aspects of emotional intelligence as measured by WLEIS comprise the same particular "themes" (items) across the two cultural groups, those themes have different importance in the calculation of the overall subscale score across the two groups. Similarly, lack of support for scalar invariance in the OEA subscale suggests that mean differences on the same item do not correspond to similar mean differences on the relevant latent variable. For example, a lower score on the item " I am a good observer of others emotions" among the Nepali compared to the UK sample would not correspond to a similarly lower score on the OEA subscale.

Differences in how individualist and collectivist cultures understand emotion may be behind such lack on invariance. Research suggests western cultures value a more open demonstration of emotion compared to the Asian (Trompenaars \& Hampden-Turner, 1998), while emotional expression among young Nepali is intrinsically linked with how social relationships are culturally constructed (Cole, Walker, \& Lama-Tamang, 2006). It may not be a coincidence that the main sources of non-invariance in our findings were the subscales relating to perceptions of self and others. Differences in how these two concepts are construed define to a large extent the distinction between individualism and collectivism (Singelis, 1994). Individualist societies like the UK value a relatively autonomous self, while collectivist societies like Nepal regard the self as an intrinsic part of a greater whole. 
For example SEA items about "understanding" as opposed to "knowing" the emotion of the self may weigh differently in the two cultures, as the former suggests a more analytic and independent inquiry while the latter a more intuitive and holistic approach to knowledge. Similarly OEA items like "I am a good observer of others emotions" may indicate a level of separation between self and other that is likely to be treated differently by respondents from the two cultures. Perhaps such cultural characteristics were uniformly present across gender only among the collectivist Nepali, as suggested by scalar non-invariance in relation to gender in the UK sample. While the observed non-invariance should be considered when interpreting these findings, the scores of Nepali men and women were similar on all subscales. On the other hand, in the UK sample male participants rated themselves lower than females in understanding others and higher in managing their own emotions, presenting a more gender-stereotypical self-description than their Nepali counterparts.

Moreover, our finding that humanities students scored higher in EI than science students in the Nepali sample was in agreement with previous research (Zhoc et al.,2020), while a weaker subscale correlation among the Nepali may suggest that, compared to the UK, individuals in a collectivist culture may not approach others as they approach the self. In collectivist cultures the evaluation of others, particularly negative evaluation, is relatively restricted so that group harmony and cohesion are maintained (Ohbuchi et al., 1999).

This study had a number of limitations that should be taken into account when the present findings are evaluated. First, the partial non-invariance of WLEIS and its two subscales should be considered when composite scores are utilised. Moreover, although the Nepali students were competent speakers of English, the questionnaire was not in their native language and that may have had an impact on how certain items were understood by 
particular students. Another limitation refers to the lack of data on the particular cultural groups Nepali student belonged to. Nepal comprises 126 different casts and ethnic groups and that diversity may have had an impact on how questionnaire items were understood. Finally, there is a slight possibility of underestimating the measurement of non-invariance due to uneven sample sizes. Yoon \& Lai (2018) report that although some degree of underestimation is likely when one sample is twice the size of the other, this is rather limited and can really become a problem when samples are severely unbalanced (e.g. a sample five or more times the size of the other). Future studies may utilise the ML-R estimation method in MPlus that can adjust for such sample differences, as an alternative to the maximum likelihood estimation used in AMOS. Future studies could also utilise Multiple Indicators Multiple Causes Modelling (MIMIC), a method that complements multi-group confirmatory factor analysis by allowing the testing of potential covariate effects. This has been used by some researchers testing measurement invariance testing across cultures (Lee at al., 2020), but was not included in the present brief study.

Future research should also aim to validate the WLEIS in Southeast Asia countries other than Nepal as well as in world regions beyond Europe and the Far East. The present study cannot be used to draw conclusions about the rest of Southeast Asia, as cultural and historical circumstances may differ significantly between countries. Future studies should also go beyond factor validity and measurement invariance, including longitudinal links with important psychosocial outcomes such as psychological well-being, quality of social relationships, and the capacity to overcome adversity. 


\section{References}

Bentler, P. M. (2006). EQS 6 structural equations program manual. Encino, CA: Multivariate Software.

Brackett, M., Mayer, J. D., \& Warner, R. M. (2004).Emotional intelligence and the prediction of behavior. Personality and Individual Differences, 36, 1387-1402. doi:10.1016/S0191- 8869(03)00236-8 .

Byrne, B. (2004). Testing for multigroup invariance using AMOS graphics, Structural Equation Modeling: A Multidisciplinary Journal, 11(2), 272-300, doi:10.1207/s15328007sem1102_8

Chen, C., Lee, S., \& Stevenson, H. W. (1995). Response style and cross-cultural comparisons of rating scales among East Asian and North American students. Psychological Science, 6(3), 170-175. doi: 10.1111/j.1467-9280.1995.tb00327.

Cole, P. M., Walker, A. R., \& Lama-Tamang, M. S. (2006). Emotional Aspects of Peer Relations Among Children in Rural Nepal. In X. Chen, D. C. French, \& B. H. Schneider (Eds.), Peer relationships in cultural context. (pp. 148-169). New York, NY: Cambridge University Press. doi: 10.1017/CBO9780511499739.007

Davis, W. L., \& Leslie, P. J. (2015). Short research report: A comparison of Emotional Intelligence levels between students in experiential and didactic college programs. The International Journal of Emotional Education, 7(2), 63-65.

Day, A. L., \& Carroll, S. A. (2004). Using an ability-based measure of emotional intelligence to predict individual performance, group performance, and group citizenship behaviours. Personality and Individual Differences, 36(6), 1443-1458. doi:10.1016/S0191-8869(03)00240-X 
D'Mello, S., \& Graesser, A. (2012). Dynamics of affective states during complex learning. Learning and Instruction, 22, 145-157.

Graham, J. M. (2006). Congeneric and (essentially) Tau-equivalent estimates of score reliability: What they are and how to use them. Educational and Psychological Measurement, 66, 930-944. doi:10.1177/0013164406288165.

Joseph, D., \& Newman, D. A. (2010). Discriminant validity of self-reported emotional intelligence: A multitrait-multisource study. Educational and Psychological Measurement, 70(4), 672-694. doi: 10.1177/0013164409355700.

Kline, R.B. (2010) Principles and Practice of Structural Equation Modeling (3rd Edition). The Guilford Press.

Kong, F. (2017). The validity of the Wong and Law Emotional Intelligence Scale in a Chinese sample: Tests of measurement invariance and latent mean differences across gender and age. Personality and Individual Differences, 116, 29-31. doi:10.1016/j.paid.2017.04.025

LaPalme, M. L., Wang, W., Joseph, D. L., Saklofske, D. H., \& Yan, G. (2016). Measurement equivalence of the Wong and Law Emotional Intelligence Scale across cultures: An item response theory approach. Personality and Individual Differences, 90, 190-198. doi:10.1016/j.paid.2015.10.045

Lee, S. T., Hartanto, A., Yong, J. C., Koh, B., \& Leung, A. K. Y. (2020). Examining the cross-cultural validity of the positive affect and negative affect schedule between an Asian (Singaporean) sample and a Western (American) sample. Asian Journal of Social Psychology, 23(1), 109-116.

Li, M., Yang, D., Ding, C., \& Kong, F. (2015). Validation of the social well-being scale in a Chinese sample and invariance across gender. Social Indicators Research, 121(2), 607-618. doi.org/10.1007/s11205-014-0639-1 
Libbrecht, N., Beuckelaer, A. D., Lievens, F., \& Rockstuhl, T. (2014). Measurement Invariance of the Wong and Law Emotional Intelligence Scale Scores: Does the Measurement Structure Hold across Far Eastern and European Countries? Applied Psychology: An International Review, 63(2), 223-237. doi: 0.1111/j.14640597.2012.00513.x

Lyubomirsky, S., King, L., \& Diener, E. (2005). The Benefits of Frequent Positive Affect: Does Happiness Lead to Success? Psychological Bulletin, 131(6), 803-855. https://doi.org/10.1037/0033-2909.131.6.803

MacCann, C., Matthews, G., Zeidner, M., \& Roberts, R. D.2004.The assessment of emotional intelligence: on frameworks, fissues, and the future. In G. Geher (Ed). Measuring Emotional Intelligence: Common Ground and Controversy (pp. 21-52). Hauppauge, NY: Nova Sci

Matsumoto, D., \& Hwang, H. S. (2011). Culture, emotion, and expression. In M. J. Gelfand, C. Chiu, \& Y. Hong (Eds.), Advances in culture and psychology, Vol. 1. (pp. 53-98). Oxford University Press.

Mayer, J. D., Roberts, R. D., \& Barsade, S. G. (2008). Human abilities: Emotional intelligence. Annual Review of Psychology, 59, 507-536. doi:10.1146/annurev.psych.59.103006.093646

Nowicki, S., Jr., \& Duke, M. P. (1994).Individual differences in the nonverbal communication of affect: The diagnostic analysis of nonverbal accuracy scale. Journal of Nonverbal Behavior, 19, 9-35. doi:10.1007/BF02169077

Ohbuchi, K. I., Fukushima, O., \& Tedeschi, J. T. (1999). Cultural values in conflict management: Goal orientation, goal attainment, and tactical decision. Journal of Cross-Cultural Psychology, 30, 51-71. doi.org/10.1177/0022022199030001003. 
Pownuk, A. \& Kreinovich, V. (2017). Why Linear Interpolation? Mathematical Structures and Modeling, 43. Retrieved from https://scholarworks.utep.edu/cstechrep/1098/

Schneider, T. R., Lyons, J. B., \& Khazon, S. (2013). Emotional intelligence and resilience. Personality and Individual Differences, 55(8), 909-914. https://doi.org/10.1016/j.paid.2013.07.460

Schultz, D., Izard, C., \& Bear, G. (2004). Children's emotion processing: Relations to emotionality and aggression. Development and Psychopathology, 16(2), 371-387. doi:10.1017/S0954579404044566.

Singelis, T. M. (1994). The measurement of independent and interdependent selfconstruals. Personality and Social Psychology Bulletin, 20, 580-591. doi.org/10.1177/0146167294205014

Trinidad, D. R., \& Johnson, C. A. (2002). The association between emotional intelligence and early adolescent tobacco and alcohol use. Personality and Individual Differences, 32(1), 95-105. https://doi.org/10.1016/S0191-8869(01)00008-3

Trompenaars, F., \& Hampden-Turner, C. (2007). Riding the Waves of Culture. New York: McGraw-Hill.

van de Schoot, R., Lugtig, P., \& Hox, J. (2012) A checklist for testing measurement invariance, European Journal of Developmental Psychology, 9, 486-492, doi:10.1080/17405629.2012.686740.

Wolf, E. J., Harrington, K. M., Clark, S. L., \& Miller, M. W. (2013). Sample size requirements for structural equation models: An evaluation of power, bias, and solution propriety. Educational and Psychological Measurement, 73(6), 913934. https://doi.org/10.1177/0013164413495237.

Wong, C., \& Law, K. (2002). The effects of leader and follower emotional intelligence on performance and attitude: An exploratory study. The Leadership Quarterly, 13, 243- 
274 (Retrieved from http://www.sciencedirect.com/science/article/pii/ S1048984302000991).

Yoon, M., \& Lai, M. H. C. (2018). Testing factorial invariance with unbalanced samples. Structural Equation Modeling, 25(2), 201-213. doi:10.1080/10705511.2017.1387859

Zhoc, K. C. H., King, R. B., Chung, T. S. H., \& Chen, J. (2020). Emotionally intelligent students are more engaged and successful: Examining the role of emotional intelligence in higher education. European Journal of Psychology of Education. doi:10.1007/s10212-019-00458-0. 


\section{Appendix 1}

Items of the WLEIS:

1. I have a good sense of why I have certain feelings most of the time.

2. I have good understanding of my own emotions.

3. I really understand what I feel.

4. I always know whether or not I am happy.

5. I always know my friend's emotions from their behaviour.

6. I am a good observer of others emotions.

7. I am sensitive to the feelings and emotions of others.

8. I have good understanding of the emotions of people around me.

9. I always get goals for myself and then try my best to achieve them.

10. I always tell myself I am a competent person.

11. I am a self-motivated person.

12. I would always encourage myself to try my best.

13. I am able to control my temper and handle difficulties rationally.

14. I am quite capable of controlling my own emotions.

15. I can always calm down quickly when I am very angry.

16. I have good control of my own emotions. 


\section{Appendix 2}

Table: Measurement invariance tests for WLEIS in relation to culture without replacing missing values.

\begin{tabular}{|c|c|c|c|c|c|c|c|c|c|}
\hline Test Variable & Model & $\begin{array}{c}\chi^{2}(d f) \\
(p)\end{array}$ & $\begin{array}{c}\Delta \chi^{2}(d f) \\
(p)\end{array}$ & RMSEA & SRMR & CFI & McD & AIC & Decision \\
\hline \multicolumn{10}{|c|}{ NEPAL SAMPLE } \\
\hline CULTURE & $\begin{array}{l}\text { Model 1: Configural } \\
\text { invariance }\end{array}$ & $\begin{array}{c}323.26(196) \\
(<.001)\end{array}$ & - & .03 & - & .95 & .91 & 339.26 & Accepted \\
\hline & $\begin{array}{l}\text { Model 2: Metric invariance } \\
\text { (comparisons with Model 1) }\end{array}$ & $\begin{array}{c}416.66(212) \\
(<.001)\end{array}$ & $\begin{array}{r}93.4(16) \\
(<.01)\end{array}$ & .04 & - & .92 & .86 & 600.68 & Rejected \\
\hline
\end{tabular}


Table1: Measurement invariance tests for WLEIS and its subscales in relation to culture.

\begin{tabular}{|c|c|c|c|c|c|c|c|c|c|}
\hline Test Variable & Model & $\begin{array}{c}\chi^{2}(d f) \\
(p)\end{array}$ & $\begin{array}{c}\Delta \chi^{2}(d f) \\
(p)\end{array}$ & RMSEA & SRMR & CFI & McD & AIC & Decision \\
\hline \multicolumn{10}{|c|}{ WLEIS } \\
\hline \multirow[t]{8}{*}{ CULTURE } & Model 1: Configural invariance & $325.75(196)$ & - & .03 & .05 & 95 & 91 & 477.75 & Accepted \\
\hline & & $(<.001)$ & & & & & & & \\
\hline & Model 2: Metric invariance & $419.96(212)$ & $94.21(16)$ & .04 & .08 & .92 & .87 & 539.96 & Rejected \\
\hline & (comparisons with Model 1) & $(<.001)$ & $(<.001)$ & & & & & & \\
\hline & \multicolumn{9}{|c|}{ SELF EMOTION APPRAISAL } \\
\hline & Model 1: Configural invariance & $17.25(4)$ & - & .07 & .03 & .97 & .99 & 49.25 & Accepted \\
\hline & & $(.002)$ & & & & & & & \\
\hline & (comparisons with Model 1) & $(<.001)$ & $(<.001)$ & & & & & & \\
\hline
\end{tabular}




\begin{tabular}{|c|c|c|c|c|c|c|c|c|c|}
\hline $\begin{array}{c}\text { Test } \\
\text { Variable }\end{array}$ & Model & $\begin{array}{c}\chi^{2}(d f) \\
(p)\end{array}$ & $\begin{array}{c}\Delta \chi^{2}(d f) \\
(p)\end{array}$ & RMSEA & SRMR & CFI & McD & AIC & Decision \\
\hline \multicolumn{10}{|c|}{ OTHER EMOTION APPRAISAL } \\
\hline \multicolumn{10}{|l|}{ CULTURE } \\
\hline & Model 1: Configural invariance & $\begin{array}{c}12.36(4) \\
(.015)\end{array}$ & - & .05 & .03 & .98 & .99 & 44.36 & Accepted \\
\hline & $\begin{array}{l}\text { Model 2: Metric invariance } \\
\text { (comparisons with Model 1) }\end{array}$ & $\begin{array}{r}29.78(8) \\
(<.01)\end{array}$ & $\begin{array}{l}17.42(4) \\
(<.01)\end{array}$ & .06 & .07 & 96 & .98 & 53.78 & Accepted \\
\hline & $\begin{array}{l}\text { Model 3: Scalar invariance } \\
\text { (comparisons with Model 2) }\end{array}$ & $\begin{array}{c}140.48(12) \\
(<.001)\end{array}$ & $\begin{array}{c}110.80(4) \\
(<.01)\end{array}$ & .12 & .07 & .76 & .93 & 172.48 & Rejected \\
\hline & Model 1: Configural invariance & $\begin{array}{c}16.51(4) \\
(.002)\end{array}$ & - & .07 & .03 & .97 & .99 & 48.51 & Accepted \\
\hline & $\begin{array}{l}\text { Model 2: Metric invariance } \\
\text { (comparisons with Model 1) }\end{array}$ & $\begin{array}{l}37.20(8) \\
(<.001)\end{array}$ & $\begin{array}{r}20.69(4) \\
(<.01)\end{array}$ & .07 & .06 & .94 & .98 & 61.20 & Accepted \\
\hline
\end{tabular}




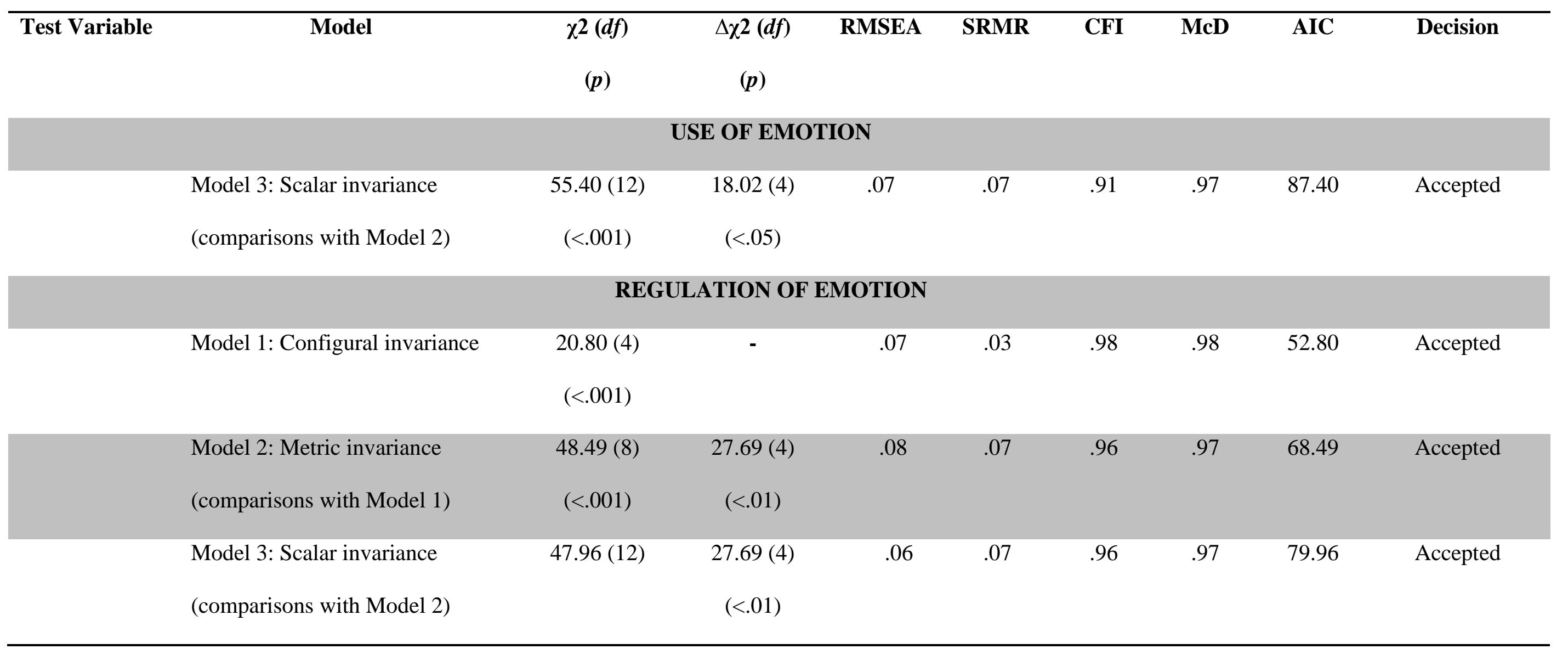


Table 2: Measurement invariance tests for WLEIS in relation to gender and subject of study.

\begin{tabular}{|c|c|c|c|c|c|c|c|c|c|}
\hline Test Variable & Model & $\begin{array}{c}\chi^{2}(d f) \\
(p)\end{array}$ & $\begin{array}{c}\Delta \chi^{2}(d f) \\
(p)\end{array}$ & RMSEA & SRMR & CFI & McD & AIC & Decision \\
\hline \multicolumn{10}{|c|}{ NEPAL SAMPLE } \\
\hline \multirow[t]{3}{*}{ GENDER } & $\begin{array}{l}\text { Model 1: Configural } \\
\text { invariance }\end{array}$ & $\begin{array}{c}246.65(196) \\
(.008)\end{array}$ & - & .02 & .05 & .95 & .93 & 398.65 & Accepted \\
\hline & $\begin{array}{l}\text { Model 2: Metric invariance } \\
\text { (comparisons with Model 1) }\end{array}$ & $\begin{array}{c}279.95(212) \\
(.001)\end{array}$ & $\begin{array}{c}33.5(16) \\
(<.01)\end{array}$ & .02 & .06 & .93 & .91 & 463.95 & Accepted \\
\hline & $\begin{array}{l}\text { Model 3: Scalar invariance } \\
\text { (comparisons with Model 2) }\end{array}$ & $\begin{array}{c}310.11(228) \\
(<.001)\end{array}$ & $\begin{array}{c}30.16(16) \\
(<.05)\end{array}$ & .02 & .06 & .92 & .89 & 462.11 & Accepted \\
\hline \multirow[t]{3}{*}{$\begin{array}{l}\text { SUBJECT } \\
\text { OF STUDY }\end{array}$} & $\begin{array}{l}\text { Model 1: Configural } \\
\text { invariance }\end{array}$ & $\begin{array}{c}387.27(294) \\
(<.001)\end{array}$ & & .03 & .07 & .91 & .79 & 615.27 & Accepted \\
\hline & $\begin{array}{l}\text { Model 2: Metric invariance } \\
\text { (comparisons with Model 1) }\end{array}$ & $\begin{array}{c}438.08(326) \\
(<.001)\end{array}$ & $\begin{array}{c}50.81(32) \\
(<.05)\end{array}$ & .03 & .07 & .89 & .85 & 602.08 & Accepted \\
\hline & Model 3: Scalar invariance & $521.95(358)$ & $83.87(32)$ & .03 & .07 & .84 & .84 & 717.95 & Accepted \\
\hline
\end{tabular}




\begin{tabular}{|c|c|c|c|c|c|c|c|c|c|}
\hline Test Variable & Model & $\begin{array}{c}\chi^{2}(d f) \\
(p)\end{array}$ & $\begin{array}{c}\Delta \chi^{2}(d f) \\
(p)\end{array}$ & RMSEA & SRMR & CFI & McD & $\overline{\text { AIC }}$ & Decision \\
\hline \multicolumn{10}{|c|}{ UK SAMPLE } \\
\hline \multirow[t]{3}{*}{ GENDER } & $\begin{array}{l}\text { Model 1: Configural } \\
\text { invariance }\end{array}$ & $\begin{array}{c}251.05(196) \\
(.005)\end{array}$ & - & .04 & .07 & .97 & .92 & 403.05 & Accepted \\
\hline & $\begin{array}{l}\text { Model 2: Metric invariance } \\
\text { (comparisons with Model 1) }\end{array}$ & $\begin{array}{c}266.78(212) \\
(.006)\end{array}$ & $\begin{array}{c}15.73(16) \\
(>.05)\end{array}$ & .04 & .08 & .97 & .88 & 386.78 & Accepted \\
\hline & $\begin{array}{l}\text { Model 3: Scalar invariance } \\
\text { (comparisons with Model 2) }\end{array}$ & $\begin{array}{c}324.26(228) \\
(<.001)\end{array}$ & $\begin{array}{c}57.48(16) \\
(<.01)\end{array}$ & .04 & .08 & .94 & .79 & 476.26 & Rejected \\
\hline
\end{tabular}


Table 3: Correlations between the four factors in the two samples.

Self Emotion Appraisal

UK: $M=15.66, S D=2.91$

Nepal: $\mathrm{M}=15.56, \mathrm{SD}=2.27$

\begin{tabular}{|c|c|c|c|}
\hline \multicolumn{4}{|l|}{ Others' Emotion Appraisal } \\
\hline UK: $M=15.60, S D=2.61$ & $\mathrm{r}=.58$ & 1 & \\
\hline \multirow[t]{2}{*}{ Nepal: $M=14.13, S D=2.67$} & $r=.44$ & & \\
\hline & $\mathrm{z}=2.36, \mathrm{p}=.018$ & & \\
\hline \multicolumn{4}{|l|}{ Regulation of Emotion } \\
\hline $\mathrm{UK}: \mathrm{M}=14.22, \mathrm{SD}=2.29$ & $r=.66$ & $\mathrm{r}=.36$ & 1 \\
\hline Nepal: $M=14.11, S D=3$ & $\mathrm{r}=.63$ & $\mathrm{r}=.38$ & \\
\hline \multicolumn{4}{|l|}{ Use of Emotion } \\
\hline UK: $M=15.40, S D=2.91$ & $\mathrm{r}=.70$ & $\mathrm{r}=.39$ & $\mathrm{r}=.59$ \\
\hline Nepal: $M=15.39, S D=2.67$ & $\mathrm{r}=.66$ & $\mathrm{r}=.38$ & $\mathrm{r}=.60$ \\
\hline
\end{tabular}

Note: For all coefficients $\mathrm{p}<.001$. For UK sample $d f=228$, for Nepali sample $d f=491$. 